\title{
Mucinous Rectal Adenocarcinoma in a Background of Chronic Schistosomiasis: A Case Report and Review of the Literature.
}

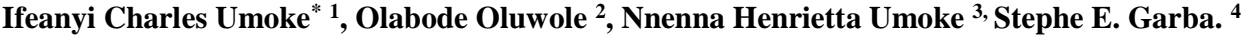

Department of Surgery, University of Abuja Teaching Hospital Gwagwalada, Abuja Nigeria

Corresponding Author: Ifeanyi Charles Umoke, Department of Surgery, University of Abuja Teaching Hospital Gwagwalada, Nigeria.

E-mail: ifeanyiumoke@gmail.com

Received Date: October 29, 2019; Accepted Date: November 4, 2019; Published Date: November 8, 2019.

Citation: Ifeanyi C Umoke, Oluwole O, Nnenna H Umoke, Stephe E. Garba, 2019) Mucinous Rectal Adenocarcinoma in a background of chronic schistosomiasis: A Case Report and Review of the Literature. Surgical Case Reports and Images, 2(1): Doi:10.31579/JSCR/2019/006

Copyright: (C2019. Ifeanyi Charles Umoke, Garba. This is an open-access article distributed under the termsof the Creative Commons Attribution License, which permits unrestricted use, distribution, and reproduction in any medium, provided the original author and source are credited.

Abstracts
Reports have revealed the existence of colonic cancer with chronic bowel schistosomiasis. The specie most frequently
involved is Schistosoma japonicum. Few cases have, however, shown Schistosoma mansoni as the involved specie.
There seems to be an association between rectal cancer and Schistosoma mansoni infestation. Despite earlier studies that
refuted any association between schistosomiasis and colonic cancer, more reports are lending credence to the claim that
chronic colonic schistosomiasis, especially with S. Japonicum, may induce colonic cancer and the case with are reporting
also point to the fact that S. Mansoni may also be implicated.
We report a case of a 35-year-old man with a rectal cancer (pT3N0M0) associated with Schistosoma mansoni. He presented
with intestinal obstruction and operation revealed a cirrhotic liver with hepatic schistosomiasis.
Key-words: schistosomiasis, rectal carcinoma, cirrhosis

\section{Introduction}

Schistosomiasis is a common communicable infestation in the tropics and sub-tropics. Human schistosomiasis is caused by three major species: schistosoma haematobium, schistosoma japonicum and schistosoma mansoni. While S. japonicum is endemic in South East Asia, S. haematobium and mansoni are prevalent in Africa and Middle East with S. mansoni also endemic in South America [1]. Schistosomiasis affect more than 200million people worldwide. Schistosoma haematobium causes bladder cancer but the association between schistosomiasis and large bowel cancer has been inconclusive with low status [2].

More evidence is emerging to support a possible causal relationship between Schistosomiasis and large bowel cancer. In fact, chronic colonic schistosomiasis should be considered a precancerous lesion [3]. We report a case of rectal cancer associated with Schistosoma mansoni and present a review of the literature.

\section{Case report (methods and results)}

We present the case of a 35-year-old male patient who lived in Suleja, North Central Nigeria (an area with Schistosoma endemicity). He presented with recurrent abdominal pain of four months duration and abdominal distension with passage of ribbon-like stools of two months duration. There was occasional passage of blood per rectum. He also had alternating periods of constipation and diarrhoea. He did not drink alcohol or smoke cigarettes.

Physical examination revealed a young man who was wasted with grossly distended abdomen with visible peristalsis. Abdomen was tense but non- tender. No palpable masses per abdomen with hyperactive bowel sounds. Digital rectal examination revealed a circumferential mass in the rectum with the narrowing of the lumen. Investigations showed a packed cell volume of $40 \%$ with normal values of electrolytes, urea and creatinine. Patient was positive for hepatitis $\mathrm{C}$ virus antigen. The liver function values were grossly deranged with total bilirubin of $26.8 \mu \mathrm{mol} / \mathrm{L}(<17 \mu \mathrm{mol} / \mathrm{L})$, unconjugated bilirubin of $11.6 \mu \mathrm{mol} / \mathrm{L}(<4.3 \mu \mathrm{mol} / \mathrm{L})$, total protein $57 \mathrm{~g} / \mathrm{L}(66-87 \mathrm{~g} / \mathrm{L})$ and albumin of $29 \mathrm{~g} / \mathrm{L}(35-52 \mathrm{~g} / \mathrm{L})$. The chest - ray was essentially normal. Abdomino-pelvic ultrasound scan revealed a shrunken liver and no intra-peritoneal fluid or collection. There is however dilated small and large guts. There were no enlarged lymph nodes. Patient was resuscitated for exploratory laparotomy. At operation, there was a grossly distended large and small bowel with an incompetent ileo-caceal valve. A circumferential mass in the recto-sigmoid junction with occlusion of the lumen and thickening of the rectal wall. There were no mesenteric lymph nodes. However, the liver was cirrhotic with no visible metastatic deposits. There was no ascites. Patient had anterior resection with colostomy and a Hartman's pouch. Abdominal distention and pain resolved following surgery. He was commenced on oral feeding consisting of high calorie, high protein diet on the 5th post-operative day. However, he developed ascites on the 7th post-operative day which progressed to anasarca with respiratory distress on the 10th post-operative day. He was placed on diuretics but subsequently went into hepatic coma and died on the 13th post-operative day.

Histology report revealed an invasive mucinous adenocarcinoma (pT3NOM0) in a background of parasitic chronic granulomatous inflammation due to Schistosoma mansoni ova. See Figures 1 and 2. 


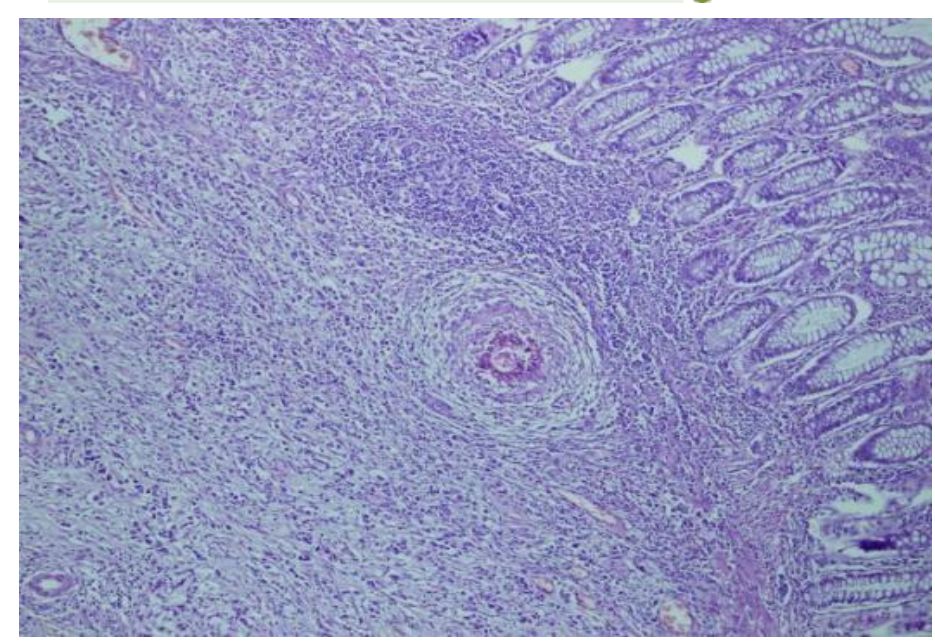

Figure 1: Calcified s. Mansoni Ova and Granuloma Formation in the Submucosa of the Sigmoid Colon. H\&e $\times 40$ [4].

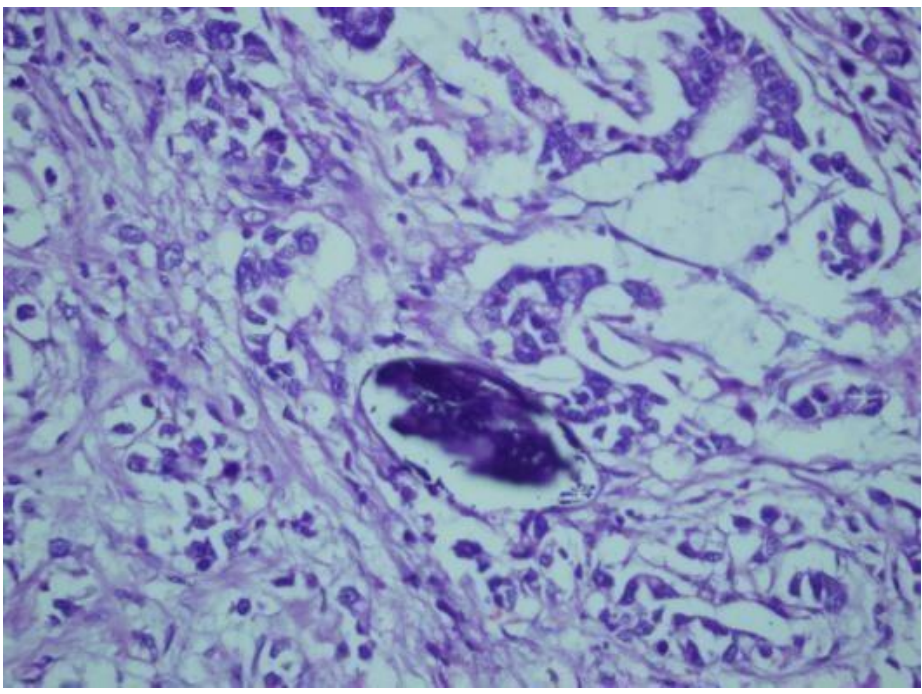

Figure 2: S. Mansoni Egg with a Characteristic Lateral Spine in a Background of Mucinous Adenocarcinoma. H\&E × 40 [4].

\section{Discussion}

It could be said that the relationship between urinary schistosomiasis and bladder cancer is well established, the same cannot be said of schistosomiasis and colonic cancer [5]. Initial reports/studies indicated no relationship. In fact, the presence of schistsoma ova/deposit in some cases of rectal cancer was coincidental according to Ibrahim [6]. Mass screening programs in china utilizing fecal occult blood and rectoscopy showed no evidence to associate schistosoma with colorectal cancer [7]. Sinatamby et al [8] in Saudi Arabia also found no evidence to support an etiological association between schistosomiasis and large bowel malignancies. Using light and electron microscopy, Li [9] studied 50 cases of colon specimen where he found non-specific changes in colon cancer with schistosomiasis, supporting other previous studies that showed no relationship between colon cancer and schistosomiasis.

However, more and more reports and studies are beginning to makeclear associations between schistosomiasis and rectal cancer.

Reviewing 276 cases of schistosomiasis due to schistosoma japonicum associated with large bowel cancer, between 1898 and 1974, shindo [10] found significant differences between carcinoma with schistosomiasis and ordinary carcinoma in symptoms, age,and sex and histological findings thereby pointing to the fact that schistosomiasis induce colonic carcinoma.
Helmstadter [11] pointed out that chronic intestinal of schistosomiasis is a potentially pre- cancerous condition.

Various types of schistosomal eggs have been linked to colorectal cancer. However, schistosoma japonicum has been more frequently implicated [10-15] followed by schistosoma mansoni [16] and schistosoma haematobium [11]. Intestinal schistosomiasis has been observed to induce various pathologic conditions including carcinoma [9,11-17], lymphoma[18], polyps[19-20], carcinoid[20] pedunculated teratoma[21]. In a hospital-based study in Uganda and Zimbabwe, Waku [22] and colleagues compared 950 cases of infective gastro-intestinal disease, particularly schistosomiasis and amoebiasis, with 249 controls admitted for various diseases other than GI disease. Further stratification of patients into three groups on the basis of the stage of the disease, acute or chronic was done. 34 patients were found to have colorectal cancer; almost all the patients had chronic schistosomiasis or amoebiasis. No colorectal cancer was detected in the other patients or control groups. The conclusion was drawn that large bowel cancer is strongly associated with chronic infectious gastro-intestinal disease [22]. Chen et al [13] noted variable degrees of colonic epithelial dysplasia in $60 \%$ of cases with s. japonicum colitis and saw it as a transition to cancer in schistosoma colonic disease. $\mathrm{Yu}$ et al [23] arrived at the same conclusion from their studies on different types of schistosomal egg polyps.

Schistosomal colorectal carcinomas seem to have a strong pre-dilection for the rectum [12].

Our patient had rectal carcinoma. Most often, a mucinous histologic type is observed [23-25], this is corroborated by our study as our patient also had mucinous adenocarcinoma.

Investigators believe the mechanism of schistosomal injury is due to endogenous production of toxin by the eggs rather than a direct carcinogenic action of the eggs [10]. Matsudo et all [12] proposed that schistosoma ova have some effect on carcinogenesis.

Hepatic schistosomiasis has also been described as the most common form of the chronic disease and is said, to result from heavy S. mansoni infestation [21].

Histologically characterized by granulomas with the subsequent formation of marked portal and perilobular fibrosis that is more serve in $\mathrm{S}$. mansoni and s. japonium infestations. Clinically, the presentation of schistosomiasis has been observed to be markedly different from that of cirrhosis with hypersplenism being dominant in schistosomiasis while hepatocellular failure is absent. Nonetheless some patients with schistosomiasis progress to an end stage of the disease with features of muscle wasting, hypo-albuminaemia, ascites and coma. The index patient was wasted, had hypo-albuminaemia, cirrhosis, ascites and coma. The terms compensated and decompensated schistosomiasis are used to differentiate patients with the sole manifestation of portal hypertension from those in whom in addition showed features of hepatocellular failure [22].

\section{Conclusion}

Despite earlier studies that refuted any association between schistosomiasis and colonic cancer, more reports are lending credence to the claim that chronic colonic schistosomiasis, especially with $\mathrm{S}$. Japonicum, may induce colonic cancer. Also, the number of cases of colonic cancer associated with schistosoma mansoni is rising.

Finally, the health dangers posed by schistosomiasis as exemplified by the case we reported is huge and thus preventive measures using periodic mass de-worming campaigns with praziquantel must not wane especially in Third World countries where the reservoir for this disease is still high.

\section{References}

1. Gryseels B, Polman K, Clerinx J, Kestens L. (2006) Human schistosomiasis. Lancet, 368 (9541): 1106-1118

2. International Agency for Research on Cancer: Infection with schistosomes, liver flukes and Helicobacter pylori. IARC 


\section{JSurgical Case Reportsand Images}

Monograms on the evaluation of carcinogenic risks to humans Lyon, France: IARC Press 1994, 61.

3. Al Mashat et al. (2001) rectal cancer associated with schistosomiasis: Report of two cases and review of literature. Annals of Saudi Medicine, vol 21 Nos1-2, 65-67.

4. Omer E H Salim, Hytham K S Hamid, Salwa O Mekki, Suleiman H Suleiman, Shakir Z Ibrahim. (2010) colorectal carcinoma associated with schistosomiasis: a possible causal relationship. World Journal of Surgical Oncology; 8:68-74.

5. Jatzko G, kleinert R, Denk H. (1997) Schistoma japonicum associated rectal carcinoma. Chirurg; 68:727-31

10. Shindo K. Significance of schistosonomiasis japonica in the development of cancer of the large intestine. Report of a case and review of literature. Dis colon Rectum, 19:460-9.

11. Helmstadter S, Ostertag-korner D, Wysockis S, Waldherr R. (1976) Schistosonomiasis and signet ring cell carcinorma of the ileo-caecal valve Dtsch Med Wouchenschr 1994: 119: 301-4

12. Mastsuda K, Masaki T, Isii S, Yamashita H, Wantanabe T, Nagawa H, et al .(1999) Possible association of rectal carcinoma with schistosoma japonicum infection and membranous nephropathy. A case report with a review. Jpn J clin oncol, 29:5768.

13. Ch'en MC Hu JC, Chang PY, Chuang CY, Ts'ao PF, Chang SH et al.(1965) Pathogenesis of carcinoma of the colon and rectum in schistosomiasis japonica. A study on 90 cases. Chin Med J, 84:513-25

14. Tokoro Y, Koganezawa S. Metrical and histopathological studies on 2 cases of Japanese schistosomiasis displaying tremendous number of eggs combined with colon cancers. Nippon Shokak Ibyo Gakkai Zasski

15. Hashimoto Y, Muratani A, Nishiyama H, Ashida H, Kurogo F, Sunono K. et al. (1986) A case of colon cancer associatied with schistosomiasis japonica. Gan. No Rinsho, 32: 815-8.

16. Chirimwami B, Okonda, L, Nelson AM. (1991) Lymphoma and schistosoma mansoni schistosomiasis. Report of 1 case. Arch Anat Cytol Pathol ,39:59-61

17. Ojo OS, Odesanmi WO, Akinola OO. (1991) the surgical pathology of colorectal cancers in Nigerians. Trop Gastroenterol ,12:180-4
6. Ibraham KA. (1977) rare turmors of the intestine and rectum. Int surg, 62:611-5

7. Zheng GM, choi BC, Yu XR, Zou RB, Shao YW. (1991) Mass screening for rectal neoplasm in Jianshang county, china. J chi Epidemol, 44:1379-85

8. Sinnatamby CS, Al-Breiki H, Al-Freihi H, Al-Idrissi H, AlQuorani Al-Hamadan A et al. (1986) Alimentary malignancies in Arabia in the Eastern Province of Saudi Arabia. Trop Geogr Medicine, 38:79-83

9. Li GR. (1989) Light and Electron microscopic studies of the relationship between colon carcinoma and schistosomiasis. Hua Hsi I ko Ta Hsueh Pao ,20:295-8

18. Robert PE, Pradel E, Brechot C, Mstine E, Hernandez C, Juilliard F. (1968) The role of rectocolonic polyposis during intestinal bilharziasis. San Hop , 44:3331-8

19. Zuckerman MJ, Goldfarb JP, Cho KC, Molnar JJ. (1983) an unusual pedunculated polyp of the colon: association with schistosomiasis. J Chin Gastroenterol, 5:169-72.

20. Satti MB, Al-Breiki H, AL-Quorani A. (1988) a rectal carcinoid in a patient with intestinal schistosomiasis: an unusual association. Trop Gastroenterol , 9:18-22

21. El-katib Y. (1972) Pedunculated teratoma of the rectum infested with bilharziasis. Br J Surg , 19:655-7

22. Waku M. Napolitano L, Clementini E, Staniscia T, Spaguollic C, Andama A, Kasiriye P, Innocent P. (2005) Risk of cancer onset in sub-Saharan Africans affected with chronic gastro-intestinal parasitic diseases. Int J immunopathol pharmacol, 18 930: 503511

23. Yu XR, Chen PH, Xu JY, Xiao S, Shan ZJ, Zhu SJ. (1991) Histological classification of schistosomal egg induced polyps of colon and their significance. An analysis of 272 cases. Chin Med J (Eng), 104(1):64-70.

24. Madbouly KM, Senagore AJ, Mukerjee A, Hussein AM, Shehata MA, Navine P, Delaney CP, Fazio VW. (2007) Colorectal cancer in a population with endemic schistosoma mansoni: is it an at-risk population? Int J Colorectal Dis, 22(2):175-181

25. Lin M, Hanai J, Gin L. (1998) Peanut lecithin-binding sites and mucins in benign and malignant colorectal tissues associated with schistosomiasis. Histol Histopathol, 13(4):961-966 